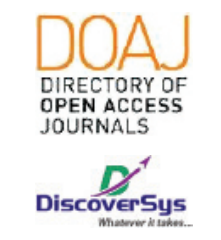

Published by DiscoverSys

\section{Assessment of quality of life among chronic kidney disease patients undergoing hemodialysis in Sanglah General Hospital, Denpasar from April-May 2017 using EQ-5D-5L questionnaire}

\author{
Ni Putu Rani Apsari Dewi, ${ }^{1 *}$ Yenny Kandarini, ${ }^{2}$ \\ I Gde Ketut Sajinadiyasa, ${ }^{2}$ Triharnoto ${ }^{2}$
}

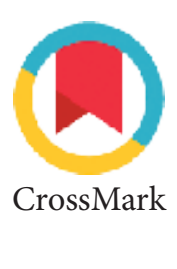


Patients with CKD frequently feel hard to perform daily activities either active or socialize, as well as to sleep because of the pain. Moreover, a variety of physical complaints often felt by the patient depends on the severity of the disease and also the complications are not the same from patient to patient. This is consistent with the theory that CKD patients will feel discomfort, tightness, edema, chest pain, nausea or even vomiting, and muscle cramps that result in severe pain. Therefore, patients are highly dependent on hemodialysis treatment to improve their quality of life. ${ }^{7,8}$ Besides physical complaints, patients undergoing hemodialysis also face another big problem. One of the most challenging issues for patients undergoing hemodialysis is the high cost of dialysis. Patients usually must pay at least five billion rupiahs (\$374.84) for dialysis therapy beyond drugs, laboratory and other ancillary medical purposes. For patients who are underprivileged of course, this is a big problem. ${ }^{3}$ Fortunately, both central and local government currently have a health financing program for people, especially the underprivileged one, where the patients can perform dialysis therapy to get relief from the cost and even free., ${ }^{3,6}$ By covering the costs of hemodialysis (HD) therapy, of course, there are some feedbacks or profit expected to the government itself. Patients are supposed to work again and improve their economic condition that will affect the government's economic or even to country. They can pay taxes and also increase per-capita income.

Quality of life is an important indicator to evaluate the outcome of hemodialysis treatment. The purpose of hemodialysis is to maintain the kidney function, thus to improve patient's quality of life. ${ }^{7}$ The worsening of their quality of life undergoing hemodialysis is not only caused by health problems that they faced related to chronic kidney disease, but also associated with treatment that lasts a lifetime. ${ }^{8}$ An international study result indicated that quality of life measures the effectiveness of medical therapy, in this case, is hemodialysis which is being a predictor of mortality among patients. ${ }^{6,8}$

\section{METHOD}

This research is a descriptive study of cross sectional design using survey technique. Samples in the study were chronic kidney disease patients (CKD) undergoing hemodialysis in Sanglah General Hospital Denpasar on April until May 2017 which matched the inclusions and exclusions criteria. This research used primary data from the patients in the form of a questionnaire. The questionnaire is EQ5D5L which are consists of two parts or pages; those are EQ-5D-5L descriptive system and the EQ Visual
Analogue scale (EQ-VAS). Data are written as a descriptive data and preserved as tables and graphs. The EQ-5D-5L descriptive system presented as a table with the frequency of reported problems for each level and each dimension. For the EQ-VAS, it performed as a graphical presentation to shows the mean of EQ-VAS scores, for example, EQ-VAS scores reported by gender for different age groups.

\section{RESULTS}

There were 49 samples collected in this research which matched the inclusions and exclusions criteria from approximately 72 questionnaires that distributed. But only 43 of 49 patients that became respondents, as six other patients had physical symptoms and refused to fill in the questionnaire.

As From Table 1, it is known that male respondents were 37 people $(86.05 \%)$, while the female was six people (13.95\%). From 43 respondents, three $(6.98 \%)$ of them were early adult (26-35), seven people (16.28\%) were late adult (36-45), 15 people (34.88\%) were in early elderly stage (46-55) and 18 people $(41.86 \%)$ were in late elderly stage (56-65) based on age category. The highest number of the educational status of respondents is in senior high school with a total of 15 people (34.88\%). A total of 17 respondents (39.53\%) were unemployed and they married with a total of 42 people $(97.67 \%)$. Most of the etiology in this research is PNC (Pyelonephritis Chronic) with the total of 37 respondents (86.05\%) and 29 people (67.44\%) had undergone hemodialysis for $\geq$ one and $\leq$ five years.

The Health-Related Quality of Life (HRQOL) as measured using EQ-5D-5L Index Value and EQ-VAS (Visual Analog Scale) Score was 0,71 \pm 0.22 and $75,7 \pm 6.35$. The distribution results of "no problem" or level 1 from each quality of life (QOL) dimension shown in Figure 1 as follows: mobility 27 (62.8\%), self-care 41 (95.3\%), usual activity 18 (41.9\%), pain or discomfort 17 (39.5\%) and anxiety or depression 22 (51.2\%).

The highest percentage among reported problems was slight problem $23(53.5 \%)$ in "usual activity" dimension. Figure 2 shows the proportion of reported problems (level 2 until 5) across five dimensions on four different age groups. Among the EQ-5D-5L dimensions, 41 respondents (95.3\%) from four age groups reported "no problem" in the dimension of "self-care". There were four respondents (9.3\%) reported "no problems" for any dimensions, one respondent (2.3\%) reported slight until severe problem for all five aspects and none reported unable or extreme.

There were significant differences among respondents group according to age, gender as well as occupation and etiology of CKD. No significant 
Table 1 Characteristics of Respondents

\begin{tabular}{|c|c|c|c|}
\hline Variabel & Total & Variabel & Total \\
\hline Gender & & Occupation & \\
\hline Male & $37(86.05 \%)$ & Employed & $26(60.47 \%)$ \\
\hline Female & $6(13.95 \%)$ & Unemployed & $17(39.53 \%)$ \\
\hline Age (years) & & Marital Status & \\
\hline $17-25$ & $0(0.00 \%)$ & Single & $2(4.65 \%)$ \\
\hline $26-35$ & $3(6.98 \%)$ & Married & $43(95.35 \%)$ \\
\hline $36-45$ & $7(16.28 \%)$ & Etiology of CKD & \\
\hline $46-55$ & $15(34.88 \%)$ & PNC & $37(86.05 \%)$ \\
\hline $56-65$ & $18(41.86 \%)$ & DKD & $6(13.95 \%)$ \\
\hline Education & & Period of Hemodialysis & \\
\hline College & $7(16.28 \%)$ & $\geq 3-\leq 12$ months & $4(930 \%)$ \\
\hline SHS & $15(34.88 \%)$ & $\geq 1-\leq 5 \mathrm{yrs}$ & $26(60.47 \%)$ \\
\hline JHS & $5(11.63 \%)$ & $\geq 5-\leq 10 \mathrm{yrs}$ & $10(23.26 \%)$ \\
\hline Elementary & $5(11.63 \%)$ & $\geq 10 \mathrm{yrs}$ & $3(6.98 \%)$ \\
\hline No Education & $11(25.58 \%)$ & & \\
\hline
\end{tabular}

Abbreviation: CKD (Chronic Kidney Disease); DKD (Diabetic Kidney Disease); PNC (Pyelonephritis Chronic); SHS (Senior High School), JHS (Junior High School).

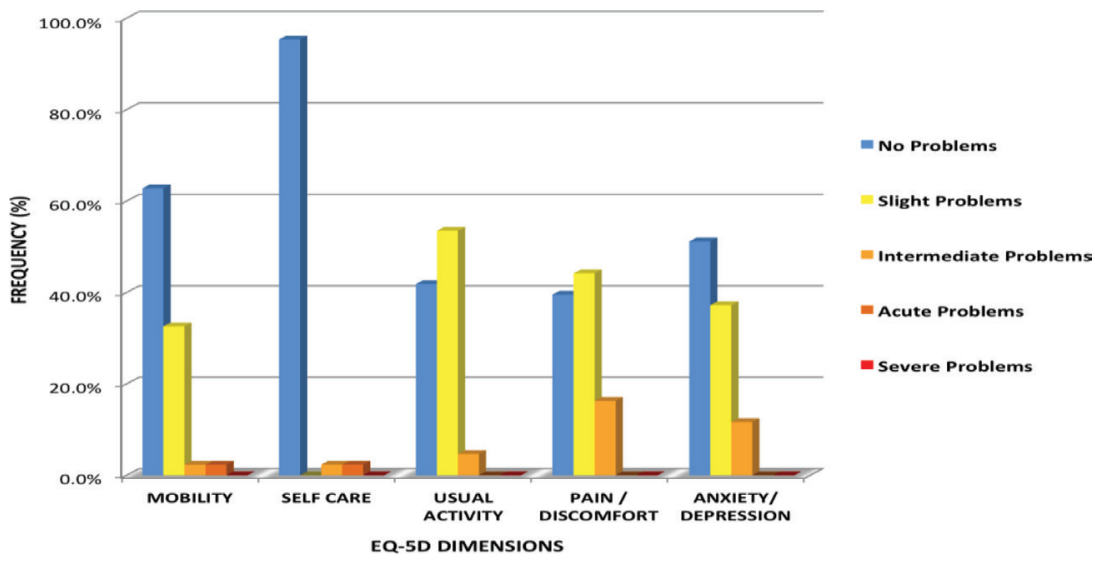

Figure 1 Distribution of health-related quality of life measures in different European quality of life scale 5 (EQ-5D)

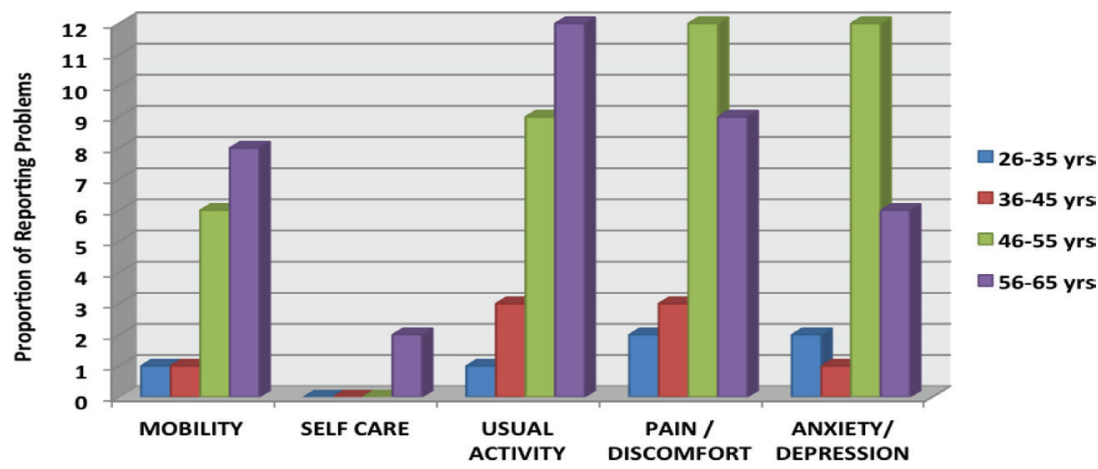

Figure 2 The proportion of reported problems by EQ-5D dimensions by age groups

differences were found among respondents group according to marital status and period of hemodialysis. The median of EQ-5D-5L index value was
0.71 (interquartile range: $0.63-0.84$ ). Figure 1 shows the mean and also the median of EQ-5D-5L index value based on the characteristics of respondents. The median of EQ-VAS was 75 (interquartile range: 70-80). As seen in Table 2, there was a significant difference among respondents according to age, gender, and occupation.

\section{DISCUSSION}

In the current study, the mean of EQ-5D-5L index value among $\mathrm{CKD}$ patients undergoing $\mathrm{HD}$ was 0.71 \pm 0.22 , while results from other studies that using the same tool in Korean, Japanese, Singaporean and Palestinian were $0.70 \pm 0.20,0.75 \pm 0.17,0.60 \pm 0.21$ and $0.37 \pm 0.44$, respectively. ${ }^{1,9,10}$ Variations of main socio-demographic and characteristics of respondents such as; age, gender, educational level, marital status, the period of HD and presence of comorbid disease could be the explanation of differences among EQ-5D-5L index value. Furthermore, Zyoud H. et al. explained that most patients in developing countries, frequently do not seek physicians until other symptoms arise. Thus, it resulted in delayed diagnosis and therapy that directly increased the number of complications then leads to a reduction of patients' HRQOL. ${ }^{1}$

This research provided that increased age was associated with lower HRQOL and it was similar findings with several previous studies using EQ-5D found that increasing age was a significant factor determining HRQOL of Korean HD patients and also cross-sectional study using EQ-5D-5L among ESRD patients in Palestine. ${ }^{1,9}$ The short duration of disease and minor complications may cause the better HRQOL in younger patients ( $<30$ years). This study also found that male gender was associated with the higher mean of EQ-5D-5L index value compared to female. This result is in agreement with study findings which is identified that poor social life and physical inactivity in developing countries might contribute to lower quality of life (QOL) scores. ${ }^{1}$

In Thailand, a study found that high educational level has a significant association with high HRQOL and it is contrary to this study. ${ }^{11}$ It happened as there was no significant difference in EQ-5D-5L index value on the educational level group. This research data also showed that being unemployed was significantly related to lower HRQOL and in agreement with a study in Palestine. ${ }^{1}$ There were no significant differences among respondents according to etiology, marital status and period of hemodialysis found in this research.

This study shows that the "usual activity" dimension influenced the HRQOL the most, followed by "pain/discomfort" and "anxiety/ depression" 
dimensions, similar to EQ-5D-5L valuation study results from England and Netherland. Meanwhile, the "self-care" dimension had the least influence on HRQOL outcomes. Quite the opposite with EQ-5D-5L value sets of Indonesia where mobility became the most influenced dimension. This is probably due to small numbers of the sample also results in small differences in translation. ${ }^{12}$ In the Indonesian translation of EQ-5D, the word 'sedih', which may also be translated as 'sadness', is added to the description of "anxiety/depression" dimension. The interaction between the dimension description and the attached value justifies the effort using the set of local and language values which is appropriate for a questionnaire utility such as EQ-5D.

\section{CONCLUSION}

In the study, most of the respondents were male. This study showed that EQ VAS score decreased as the age of respondents increased. The "usual activity" dimension influenced the HRQOL the most, followed by "pain/discomfort" and "anxiety/ depression" dimensions. Meanwhile, the "self-care" dimension had the least influence on HRQOL outcomes. Elderly patients, female gender, and unemployed patients were all associated with poor HRQOL. These results are expected to be of interest to educators, pharmacists, and clinicians working with ESRD patients. Healthcare providers should be aware of low HRQOL among patients with, female gender, elderly and also unemployed patients to improve their QOL.

\section{LIMITATION}

This research still has several limitations. First, this is a cross-sectional study so a causal relationship might not be directly derived. Second, convenience sampling technique was used that could decrease the generalization of the results. Recognizing the health status of chronic kidney disease (CKD) patients undergoing hemodialysis (HD) and identifying factors significantly associated with their health-related quality of life (HRQOL) could serve as useful indicators for health policymakers, regulators, and researchers to make effective and efficient strategies to improve the outcome and patient-centered care in the future.

\section{REFERENCES}

1. Zyoud H, Daraghmeh DN, Mezyed D, Khdeir R, Sawafta M, Ayaseh NA, et al. Factors Affecting Quality of Life in Patients on Haemodialysis: A Cross-Sectional Study from Palestine. Bio-Medical Centre Nephrology. 2016: 17(2); 44-56

2. Kidney Disease: Improving Global Outcomes (KDIGO) CKD Work Group. Clinical Practice Guideline for the Evaluation and Management of Chronic Kidney Disease. Kidney International Supplements. 2013: 1(3); 1-150.

3. Prodjosudjadi W and Suhardjono A. End-Stage Renal Disease in Indonesia: Treatment Development. Ethnic and Disease. 2009: 19(1); S1-36.

4. The United States Renal Data System (USRDS). Annual Data Report Volume 1: Chronic Kidney Disease. Chapter 1: Chronic Kidney Disease (CKD) in General Population. 2016. [Online] Available from: https://www.usrds. org/adr. aspx. Accessed on $2^{\text {nd }}$ December 2016.

5. Australian Institute of Health and Welfare (AIHW). Chronic Kidney Disease. 2016. [Online] Available from: http://www.aihw.gov.au/chronic-kidney-disease. Accessed on $3^{\text {rd }}$ December 2016.

6. Indonesian Renal Registry (IRR). 5th Annual Report of Indonesian Renal Registry 2012. Perhimpunan Nefrologi Indonesia (PERNEFRI). 2013.

7. Cruz MC, Andrade C, Urrutia M, Draibe S, Antonio L and Castro R. Quality of Life in Patients with Chronic Kidney Disease. Clinical Science. 2011: 66(6); 991-995.

8. Gerasimoula K, Lefkothea L, Maria L, Victoria A, Paraskevi T and Maria P. Quality of Life in Haemodialysis Patients. Mater Sociomed. 2015: 27(5); 305-309.

9. Kang GW, Lee IH, Ahn KS, Lee J, Ji Y, Woo J. Clinical and Psychosocial Factors Predicting Health-Related Quality of Life in Hemodialysis Patients. Hemo-dialysis International. 2015: 9(3); 439-46.

10. Katayama A, Miyatake N, Nishi H, Uzike K, Sakano N, Hashimoto $\mathrm{H}$, et al. Evaluation of Physical Activity and its Relationship to Health-Related Quality of Life in Patients on Chronic Hemodialysis. Environmental Health and Preventive Medicine. 2014: 19(3); 220-5.

11. Sakthong P and Kasemsup V. Health Utility Measured with EQ-5D in Thai Patients undergoing Peritoneal Dialysis. Value Health. 2012: 15(1); S79-84.

12. Maryam, Y., Sima, R., Omid, K., Elmira, M., Mina, J., Samaneh, S., Mohammad, E. 2017. A systematic review of factors influencing healthcare services marketing in Iran. Bali Medical Journal 6(2): 268-278. DOI: 10.15562/bmj. v6i2.536

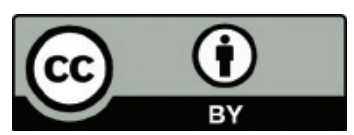

This work is licensed under a Creative Commons Attribution 